\title{
Plankton community properties determined by nutrients and size-selective feeding
}

\author{
Heidi L. Fuchs ${ }^{1,2, *}$, Peter J. S. Franks ${ }^{2}$ \\ ${ }^{1}$ Institute of Marine and Coastal Sciences, Rutgers University, New Brunswick, New Jersey 08901, USA \\ ${ }^{2}$ Scripps Institution of Oceanography, University of California - San Diego, La Jolla, California 92093, USA
}

ABSTRACT: The potential impacts of climate change on marine planktonic ecosystems remain difficult to predict. Climate forcing can alter nutrient availability and predator community composition, and here we show that these shifts may dramatically alter plankton trophic structure, size distributions and biomass. We modeled phytoplankton and zooplankton as a highly resolved size spectrum with size-dependent nutrient uptake and predation and analyzed the model both as a size spectrum and as a food web. Model results identified 2 distinct regimes defined by the average zooplankton feeding preferences. Regime I communities, where planktonic predators are specialists or large relative to prey, had low omnivory, many top predators, low connectance and relatively flat size spectra. Regime II communities, where predators are generalists or small relative to prey, had a high degree of omnivory, no top predators, high connectance and steep size spectra. Model ecosystems with generalist predators had lower size diversity, smaller plankton and gappier size distributions than ecosystems with specialist predators. Nutrient availability had little influence on trophic structure but strongly impacted size structure and biomass. Most surprisingly, phytoplankton biomass sometimes decreased with added nutrients if predators were small relative to prey, implying that both predators and nutrients mediate shifts between bottom-up and top-down control. Based on our synthesized estimates of size-selective feeding parameters, we infer that size and trophic structure should be strongly affected by abundances of generalist, bloom-forming taxa such as salps and jellyfish, many of which are responsive to ocean temperature. Size-selective feeding fundamentally affects community structure and is a likely mechanism of change in planktonic ecosystems where community composition varies with temperature.

KEY WORDS: Size spectra - Food web - Ecosystem • Predator-prey interaction · Plankton dynamics

Resale or republication not permitted without written consent of the publisher

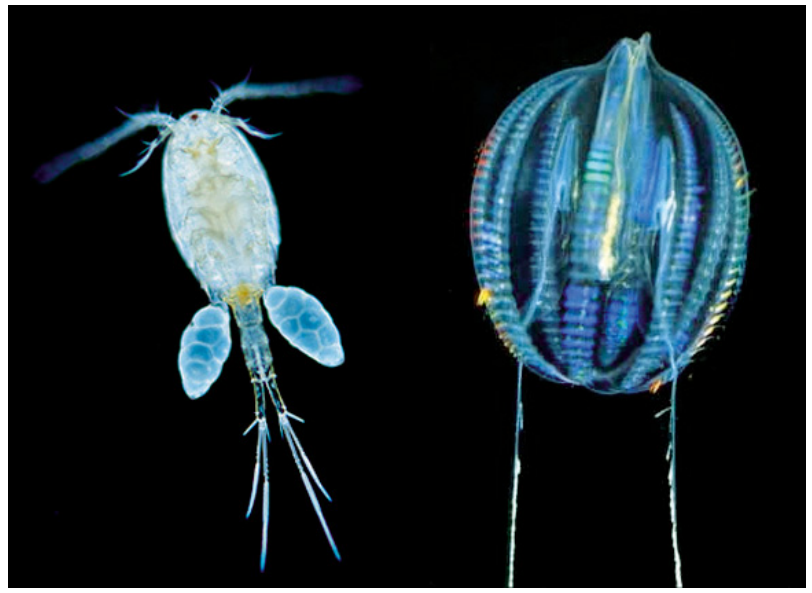

Plankton communities dominated by taxa with different feeding preferences (e.g. copepods vs. ctenophores) have distinct food webs with different size structures and responses to nutrient inputs.

Photos: Wim van Egmond and David Wrobel

\section{INTRODUCTION}

Rising sea surface temperatures (SSTs) have complex effects on plankton productivity, and some mechanisms by which ocean warming affects plankton communities remain unknown. Roemmich \& McGowan (1995) suggested that because warmer waters are more stratified, higher SSTs will lead to nutrient limitation of phytoplankton growth and reduced plankton productivity (bottom-up effect). This hypothesis is supported by data showing a negative relationship between SST and primary productivity in ocean regions that are permanently stratified (Behrenfeld et al. 2006) or seasonally stratified and relatively warm and nutrient-poor (Richardson \& Schoeman 2004). In some 
cooler regions of the North Atlantic, however, rising SSTs have been accompanied by higher biomass, presumably because these waters were already nutrientrich (Richardson \& Schoeman 2004). In the North Sea, warming periods have resulted in more phytoplankton biomass despite reduced nutrient availability, an outcome that other physical factors such as water transparency cannot fully explain (McQuatters-Gollop et al. 2007). It is difficult to understand these patterns by invoking only bottom-up effects, and climate cycles may also affect plankton productivity through topdown processes.

Climate-driven shifts in the predator community could affect the productivity and biomass distribution of lower trophic levels through top-down control of plankton size structure. In the California Current, for example, the long-term CalCOFI program has shown that warm (positive) and cool (negative) phases of the Pacific Decadal Oscillation (PDO) favor different groups of planktonic predators. For our purposes a predator can be an herbivore, an omnivore or a carnivore. Taxa including foraminifera (Field et al. 2006), copepods (Hooff \& Peterson 2006), krill (Brinton \& Townsend 2003), salps (Lavaniegos \& Ohman 2003, Hereu et al. 2006) and fish (Smith \& Moser 2003) exhibit SST-associated shifts in species composition and abundance. Predators have within- and amongtaxa variation in their feeding modes and anatomy, such that different predators eat different size ranges of prey. The average prey-size selectivity of the community may change due to climate-driven shifts in the predator community composition, with consequences for plankton size structure.

Plankton size distributions are the product of individual-level processes, such as growth and mortality, and community interactions, including competition and predation. Many physiological rates are a function of organism size (allometric scaling; Moloney \& Field 1989, Brown et al. 2004); for example, smaller cells can grow faster and are better able to compete for nutrients supplied through molecular diffusion. Predation is also size-dependent in that the strength of trophic links between predators and their prey is determined by the predator-prey size ratio (Cohen et al. 1993). Although size is not the only criterion of prey selection, it is the most universal, and most planktonic predators are $\leq 100$ times larger than their prey (Hansen et al. 1994).

The predator-prey size ratio has long been appreciated as an important aspect of trophic interactions (Sheldon et al. 1977); ecosystems with larger predator-prey size ratios generally have fewer trophic levels and more efficient transfer of biomass from small organisms to large ones (Jennings et al. 2002). Another aspect of trophic interactions, one that has received less attention, is the size range of prey that predators can ingest. Prey size ranges for different predators vary over orders of magnitude and are appropriately considered on a $\log _{10}$ scale. Specialist predators consume a narrow range of prey sizes, and their feeding moves biomass from small to large organisms over relatively discrete size intervals. Generalist predators consume a wider range of prey sizes, redistributing biomass over more diffuse size intervals. Recent work (e.g. Law et al. 2009) has focused more attention on the role of prey size ranges in structuring an ecosystem.

Size-dependent predation is a useful framework for modeling plankton communities and provides a logical link between static and dynamic food webs (Cohen et al. 1993, Neubert et al. 2000). Traditional theoretical food webs use simple rules to predict the structure of linkages among species or groups in a web. The cascade model, for example, depends only on the number of species $(S)$ and the number of trophic links $(L)$ (Cohen \& Newman 1985). The cascade model and its descendants generate webs with statistical properties that can be measured in real food webs. Trophic properties include the fractions of top predators, intermediate species (both predators and prey) and basal prey species, the fractions of herbivores, omnivores and carnivores, and connectance $\left(L / S^{2}\right)$. Models that link species based on predator-prey size relationships are more stable and better predictors of real food webs than models without explicit size structure (Neubert et al. 2000, Brose et al. 2006b, Neutel et al. 2007, Petchey et al. 2008). Size structure may also be implicit or explicit in dynamic ecosystem models that predict changes in nutrients, phytoplankton and zooplankton (NPZ models; e.g. Steele \& Henderson 1981, Franks et al. 1986). In contrast to food webs, these models depend on rate processes, are highly aggregated and can predict community properties such as biomass and the shape of the size spectrum (Armstrong 2003, Stock et al. 2008) without specifying food web structure.

Here we developed a model of nutrients, phytoplankton and zooplankton with nearly continuous size distributions and analyzed the model both as a size spectrum and as a food web. The discrete version of the model has highly resolved size classes that can be treated as distinct size-species. At steady-state these size-species are trophically linked in a web that has parameter-dependent trophic structure (\% omnivory, connectance, etc.) and size structure (size spectrum slope and nonlinearity). The model shows that both the predator-prey size ratio and the prey size range have substantial effects on fundamental properties of a plankton community. We also synthesized data on size-selective feeding of zooplankton to make general predictions about how the abundance of particular zooplankton taxa is likely to affect community structure. 


\section{METHODS}

Estimating size-selective feeding parameters. We estimated size-selective feeding parameters for planktonic invertebrates based on prey size distributions compiled from the literature (Table S1 in the supplement at www.int-res.com/articles/suppl/m413p001_ supp.pdf). Data were taken from the text and tables if possible or estimated by eye from figures. Some predator size ranges were pooled or broken down into smaller size classes if a large range of predator sizes was included (noted in Table S1). We used authors' size measurements whenever possible in terms of equivalent spherical diameter (ESD) or length. Size was usually expressed as prosome length for copepods, bell diameter for medusae and length for other gelatinous taxa (salps, doliolids, siphonophores and ctenophores) and krill. For chaetognaths we assumed a cylindrical volume with dimensions of head width and body length; when only one measurement was provided, we used Pearre's (1980) equations relating these dimensions. We excluded studies in which predator sizes were omitted or the size range of prey offered in feeding experiments was too limited.

Feeding parameters were based on the size ranges of predators and their prey. We estimated the mean $\log _{10}$ predator-prey size ratio $(m)$ as the difference between the mean $\log _{10}$ predator size and the mean $\log _{10}$ prey size. We estimated the prey size range as the total range of prey in gut contents or as the range of positive clearance or electivity in feeding experiments. We then estimated the standard deviation as one-sixth the $\log _{10}$ prey size range based on the observation that if prey sizes were normally distributed on a $\log _{10}$ scale, then $99.7 \%$ of prey would be within 3 standard deviations of the mean. Note that if prey sizes have any other distribution, then at least $89 \%$ of prey are within 3 standard deviations of the mean by Chebyshev's inequality. Therefore, the shape of the feeding distribution has little effect on the accuracy of our standard deviation estimates, contributing an error of $\leq 1.8 \%$ of the prey size range. We assumed a symmetrical distribution of $\log _{10}$ prey sizes because for most predators the optimal prey size was close to the mean of the $\log _{10}$ prey size range. Some $\log _{10}$ prey size ranges had sharp peaks, suggesting a Laplace distribution.

Community feeding distribution. A feeding size distribution can be expressed at levels ranging from the individual to the entire community; we simplified our approach by exploring feeding distributions at the community level. On a linear size scale, large invertebrate predators tend to have a greater mean predator-prey size ratio and a wider prey size distribution than small predators (Hansen et al. 1994). On a $\log _{10}$ size scale, however, predator-prey size ratios vary little; $\log _{10}$ ratios for plankton are typically between 0 and 3 regardless of predator size. We assume that on a $\log _{10}$ scale the mean predator-prey size ratio and prey size range can be expressed as a community average. This community-average feeding distribution is independent of predator size, yet retains the linear-scale differences in prey size distributions expected for a continuum of predator sizes. Although a communitylevel feeding distribution may be inaccurate for component species, there should be a single distribution that best represents the aggregated community.

Ideally the community feeding distribution should be estimated by plotting on a $\log _{10}-\log _{10}$ scale the prey size vs. predator size for all trophically linked pairs of organisms in an ecosystem. The slope of a linear regression through these points would give the mean prey-predator size ratio, the standard deviation of residuals would give the standard deviation of the $\log _{10}$ prey size distribution and the frequency distribution of residuals would give the shape of the best community feeding distribution. Using this approach, Brose et al. (2006a) analyzed predator and prey sizes from marine and terrestrial ecosystems and found a strong linear correlation between predator size and prey size. The residuals indicated a non-normal distribution. A uniform distribution is also unlikely, because a combination of strong and weak interactions is necessary for food-web stability (McCann et al. 1998). The shape of the feeding distribution is equivocal even for well-studied calanoid copepods (Steele \& Frost 1977), and additional data are needed to find the best community-level feeding distribution. A Laplace distribution cannot be ruled out and was used in the present study.

Size-resolved NPZ model. We explored the effects of nutrients and community-level feeding preferences on lower trophic levels using an NPZ model where plankton size is continuous:

$$
\begin{gathered}
N(t)=N_{\mathrm{T}}-\int P(x, t) \mathrm{d} x-\int Z(x, t) \mathrm{d} x \\
\frac{\partial P(x, t)}{\partial t}=P(x, t)\left(-\lambda+\mu_{\max }(x) \frac{N(t)}{N(t)+k_{\mathrm{s}}}-g \int F^{-}(x, y) Z(y, t) \mathrm{d} y\right) \\
\frac{\partial Z(x, t)}{\partial t}=Z(x, t)\left(-\delta-g \int F^{-}(x, y) Z(y, t) \mathrm{d} y+\right. \\
\left.\gamma g \int F^{+}(y, x)[P(y, t)+Z(y, t)] \mathrm{d} y\right)
\end{gathered}
$$

where $t$ is time, $x$ and $y$ are size expressed as $\log _{10}$-ESD, $\lambda$ and $\delta$ are the natural mortality rates of phytoplankton and zooplankton, respectively, $\mu_{\max }$ is the maximum specific growth rate of phytoplankton, $k_{\mathrm{s}}$ is the half-saturation constant for growth, $g$ is a feeding rate, $\gamma$ is an assimilation coefficient, $F^{-}$is the feeding preference kernel, $F^{+}$is the biomass redistribution kernel, $N_{\mathrm{T}}$ is the total nutrient in the system, $N$ is the free nutrient, and $P$ and $Z$ are phytoplankton and zoo- 

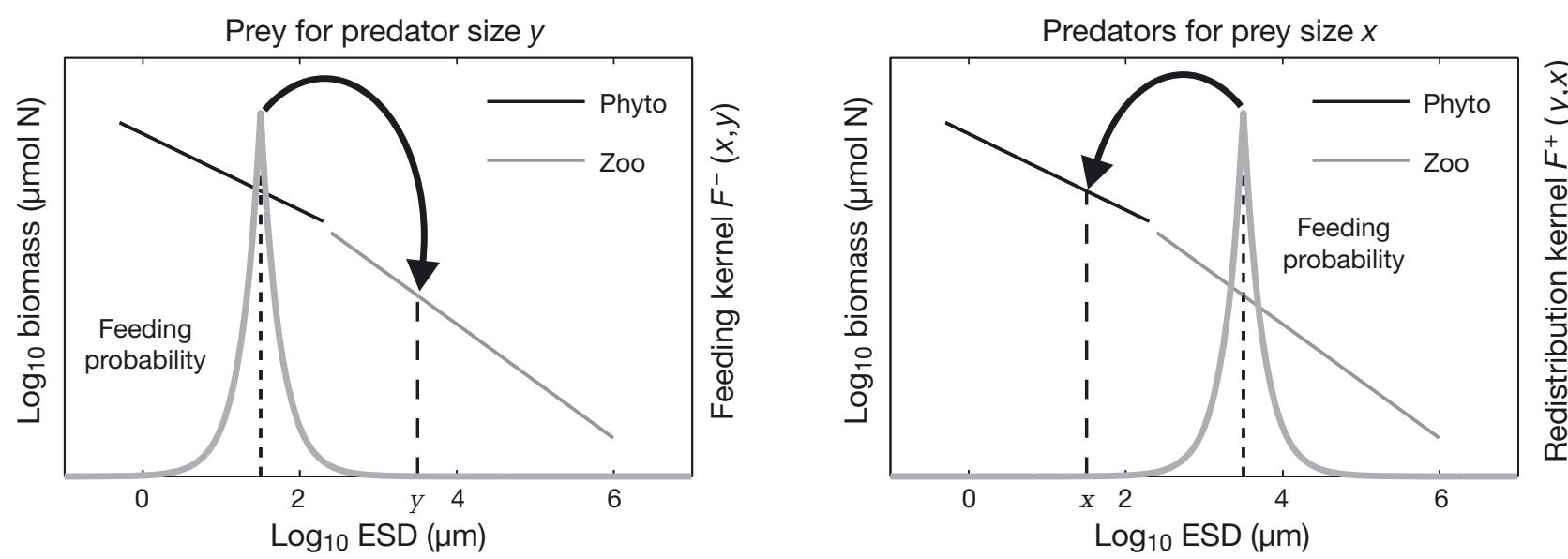

Fig. 1. Schematic of size-structured nutrients, phytoplankton and zooplankton (NPZ) model showing the size-selective feeding mechanism. Both phytoplankton and zooplankton have biomass distributed over a range of equivalent spherical diameter (ESD). Predators of a given size (here $y=3.5 \log _{10}$ ESD $\mu \mathrm{m}$ ) feed on a prey size range with probability distribution given by the feeding kernel $F^{-}$. In turn, prey of a given size (here $x=1.5 \log _{10}$ ESD $\mu \mathrm{m}$ ) are eaten by a predator size range with probability given by the redistribution kernel $F^{+}$. The mean predator-prey size ratio is $m=2$ and the standard deviation of the prey size distribution is $s=0.25$

plankton biomass, respectively. Here light, temperature, $N_{\mathrm{T}}, \lambda, g, \delta$ and $\gamma$ are constants. This size-spectrum encompasses much more plankton diversity than a typical NPZ model, yet requires few additional parameters.

This model has size dependence in what we consider to be the dominant size-structured processes: phytoplankton growth and the zooplankton feeding preference. The phytoplankton maximum specific growth rate scales with organism size as $\mu_{\max }=$ $a \mathrm{ESD}^{b}$, where $a$ is an allometric coefficient and $b$ is an allometric scaling exponent. Predators distribute their feeding based on predator-prey size ratios. The probability that zooplankton of size $y$ will eat prey of size $x$ is given by the feeding kernel $F^{-}(x, y)$, defined by the mean $\log _{10}$ prey-predator size ratio $-m$ and the standard deviation of the $\log _{10}$ prey size distribution $s$. Likewise, the probability that prey of size $x$ will be eaten by zooplankton of size $y$ is given by the redistribution kernel $F^{+}(y, x)$ defined by the mean $\log _{10}$ predator-prey size ratio $m$ and $s$. Note that $F$ is not a species-level property, but rather a community-level representation of the aggregated feeding distribution of all organisms of a given size. We use a Laplace distribution for $F$ because it is plausible and produces smooth size spectra (H. L. Fuchs \& P. J. S. Franks unpubl. data). Because $F$ is a probability distribution, its integral must equal 1, and the maximum feeding probability $\left(F_{\max }\right)$ decreases as $s$ increases. Predatorprey encounters are assumed to be random, so zooplankton eat both phytoplankton and zooplankton in a given size class in proportion to their abundances (Fig. 1). This simple model includes size-dependent, bottom-up and top-down effects.
Parameter selection. To explore the effects of sizeselective feeding, we used a fixed $N_{\mathrm{T}}$ of $5\left(N_{\mathrm{T}}=10 \mathrm{in}\right.$ Fig. 3) and varied $m$ and $s$, the parameters that define the feeding distribution. Hereafter, we refer to $m$ and $s$ as feeding parameters. The ranges of $m$ and $s$ were selected to encompass the full range of zooplankton feeding parameters calculated from the literature. To understand how nutrients affect community properties, we varied the total nutrient between 1 and $30 \mu \mathrm{mol} N$ for several combinations of $m$ and $s$ that were chosen from throughout the feeding parameter space.

In order to focus on how size-structured feeding and nutrients affect community properties, we held other parameters constant (Table 1). The exponent $b$ describes the allometric dependence of the maximum phytoplankton growth rate on ESD. This exponent traditionally has been estimated with reference to volume. A volume-specific scaling exponent of -0.21 was found by Tang (1995), and a similar value of -0.25 was assumed by Moloney \& Field (1989). Because we defined size by ESD, the scaling exponent $b$ is onethird the volume-specific exponent; we used $b=-0.75$. For the assimilation coefficient $\gamma$ we used the value suggested by Edwards et al. (2000) for microzooplankton. The zooplankton mortality rate $\delta$ approximated the value used in Edwards et al. (2000) and Franks et al. (1986). We selected the phytoplankton mortality rate $\lambda$, the half-saturation constant $k_{\mathrm{s}}$ and the feeding rate $g$ as values that allowed plankton to persist over a reasonable range of size classes. We used a small value of $\lambda$ and assumed that most phytoplankton mortality is due to predation. Our $k_{\mathrm{s}}$ is on the order of the value used by Moloney \& Field (1991) for microphytoplankton. Our value of $g$ was deemed reasonable because it 
Table 1. Symbol definitions and parameter values

\begin{tabular}{|llll|}
\hline Name & \multicolumn{1}{c}{ Description } & Value & Units \\
\hline$x$ & Log ${ }_{10}$ ESD & & $\log _{10} \mu \mathrm{m}$ \\
ESD & Equivalent spherical diameter & & $\mu \mathrm{m}$ \\
$P$ & Phytoplankton biomass & & $\mu \mathrm{mol}$ \\
$Z$ & Zooplankton biomass & & $\mu \mathrm{mol}$ \\
$N$ & Free nitrogen & & $\mu \mathrm{mol}$ \\
$F^{-}$ & Feeding kernel & & \\
$F^{+}$ & Redistribution kernel & & \\
$N_{\mathrm{T}}$ & Total nitrogen in system & $1-30$ & $\mu \mathrm{mol}^{b}$ \\
$a$ & Allometric coefficient & 5 & $\mu \mathrm{m}^{b} \mathrm{~d}^{-1}$ \\
$b$ & Allometric exponent & -0.75 & \\
$g$ & Feeding rate & 7 & $\mu \mathrm{mol} \mathrm{d}^{-1}$ \\
$k_{\mathrm{s}}$ & Half-saturation constant & 35 & $\mu \mathrm{mol}$ \\
$m$ & Mean of feeding kernel & $0.3-4.0$ & $\log _{10} \mu \mathrm{m}$ \\
$S$ & SD of feeding kernel & $0.01-0.5$ & $\log _{10} \mu \mathrm{m}$ \\
$\gamma$ & Assimilation efficiency & 0.7 & \\
$\delta$ & Zooplankton mortality & 0.17 & $\mathrm{~d}^{-1}$ \\
$\lambda$ & Phytoplankton mortality & 0.017 & $\mathrm{~d}^{-1}$ \\
$\mu_{\text {max }}$ & Maximum P growth rate & $a \mathrm{ESD}$ & $\mathrm{d}^{-1}$ \\
\hline
\end{tabular}

gave maximum ingestion rates $\left(I_{\max }=g F_{\max } P(x, t)\right.$, $\sim 0.01$ to $\sim 1.0 \mathrm{~d}^{-1}$ at equilibrium) that agreed well with values reported by Hansen et al. (1997).

Numerical solution. We solved the model system numerically using Matlab. We discretized the equations using a forward difference in time to write the model as a set of coupled integro-difference equations (IDEs). IDEs are frequently used to model the dispersal of one or more populations in space (e.g. Neubert et al. 1995). The evolution of $N, P$ and $Z$ was treated as a discrete-time, 2-step operation, with the non-interactive terms (nutrient uptake and natural mortality) and interactive terms (herbivory and predation) separated by half time steps ( $\Delta t=1 \mathrm{~d})$. We discretized the equations with respect to size $\left(\Delta x=7.8 \times 10^{-3} \log _{10} \mu \mathrm{m}\right)$, padded the size axis for a total of 1024 size classes and solved the convolution integrals using fast Fourier transforms (Kot et al. 1996) with a quasi-second order Adams-Bashforth explicit difference scheme for the time integration.

All model runs were initialized with 346 size classes for $P(\mathrm{ESD}=0.8$ to $400 \mu \mathrm{m})$ and 512 classes for $Z(\mathrm{ESD}=$ 1 to $10000 \mu \mathrm{m})$, using initial spectral slopes (biomass vs. $\log _{10}$ volume, unnormalized) of 0 as suggested by the linear biomass hypothesis (Sheldon et al. 1972). The total available nutrient was initially distributed as $20 \% N, 10 \% P$ and $70 \% Z$. The initial zooplankton biomass had to be unnaturally high because it was spread over a wider size range than could be supported at equilibrium. It is numerically difficult to find exact equilibria for hundreds of size classes simultaneously, so we considered the solution to be at steady state when $\Sigma P$ and $\sum Z$ changed by less than $10^{-10} \mu \mathrm{mol} \mathrm{N}$ per time step. The model reaches steady states over a broad range of feeding kernel parameters as long as the predators are larger than their prey on average $(m \geq 0.3)$.

The discretized version of the model was highly resolved, enabling us to estimate properties of trophic structure that are commonly calculated for food webs, and properties of size structure that are a focus of dynamic size-spectrum models. To classify plankton by trophic types, we counted all phytoplankton size classes as basal species and classified the zooplankton into top and intermediate predators by calculating the feeding probability $F(x, y)$ between all zooplankton size-class pairs that persisted at equilibrium. Zooplankton size classes with a $<10^{-5}$ probability of being eaten were counted as top predators, and all others were counted as intermediate. Zooplankton size classes were counted as herbivores, carnivores or omnivores based on whether they ate only phytoplankton, only zooplankton or both types, respectively. Connectance is given by $C=L / S^{2}$, where $L$ is the number of realized trophic links and $S^{2}$ is the number of possible links, with $S$ given by the total number of size classes with biomass $\geq 10^{-10} \mu \mathrm{mol}$ in both phytoplankton and zooplankton. Links were considered realized if there was a $>10^{-5}$ probability that the predator size class consumed the prey size class. Threshold values were chosen arbitrarily; a feeding probability of $10^{-5}$ was at least 6 standard deviations from the mean for all feeding parameters, and biomass dropped rapidly to zero below $\sim 10^{-10} \mu \mathrm{mol} N$. Plankton size diversity is the number of $P$ and $Z$ size classes containing biomass $\geq 10^{-10} \mu \mathrm{mol}$. We calculated the slope and $\mathrm{R}^{2}$ of the combined $P$ and $Z$ spectra, normalized by the width of the size classes, using a linear regression of $\log _{10}$ biomass vs. $\log _{10}$ ESD. There are several ways that the combined spectrum can deviate from a straight line: different segments of the spectra can have different slopes, the 2 spectra can overlap, the spectra can have wiggles in otherwise-straight segments or the spectra can have large peaks and gaps. We used $\mathrm{R}^{2}$, the coefficient of determination, as a measure of nonlinearity arising from these spectral characteristics. Finally, the total biomass is the sum of biomass in all $P$ and $Z$ size classes of the un-normalized spectra.

The average trophic level of each zooplankton size class is:

$$
T_{\mathrm{Z} i}=1+\frac{\sum_{j=1}^{n} \alpha_{\mathrm{Pj}} T_{\mathrm{P}}+\alpha_{\mathrm{Zj}} T_{\mathrm{Z} j}}{n}
$$

where $T_{\mathrm{P}}=1$ is the trophic level of phytoplankton, $T_{\mathrm{Zi}}$ is the trophic level of zooplankton in size class $i, j$ is a dummy variable for size class, $\alpha_{\mathrm{P} j}$ and $\alpha_{\mathrm{Zj}}$ are the autotrophic and heterotrophic fractions of biomass in size class $j$ and $n$ is the number of zooplankton size classes that persist at equilibrium. From individual size 


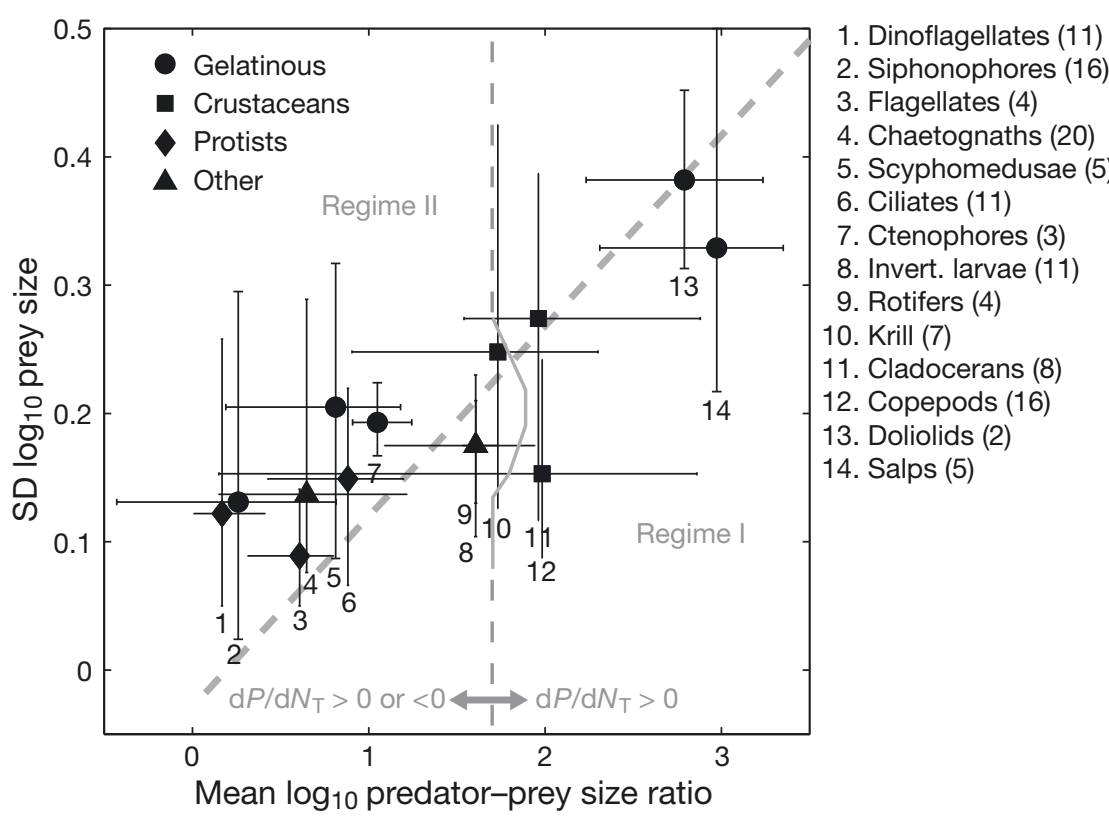

Fig. 2. Feeding distribution parameters for major taxa estimated from size-selective feeding literature (see Table S1 in the Supplement at www.int-res.com/articles/suppl/m413p001_supp.pdf for species names and sources). Estimates are given as a mean (symbols) and range (bars), and the number of estimates used for each taxon is given in parentheses in the key. Diagonal dashed line indicates boundary between Regime I and Regime II parameter spaces. Vertical dashed/solid grey line indicates boundary between parameter regions where $\mathrm{d} P / \mathrm{d} N_{\mathrm{T}}$ is always positive (right of the line) and sometimes negative (left of the line), as indicated in Fig. 8

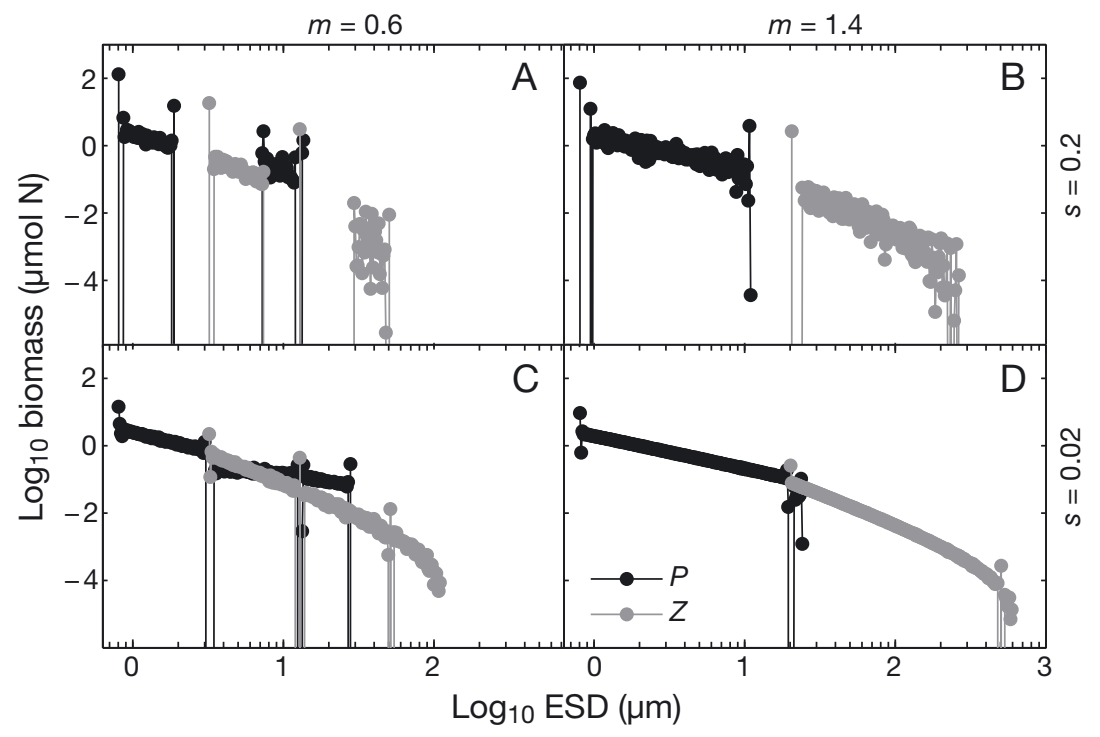

Fig. 3. Examples of plankton size spectra with different feeding distribution parameters. (A) $m=0.6, s=0.02$; (B) $m=1.4, s=0.02$; (C) $m=0.6, s=0.2$; and (D) $m=1.4, s=0.2$. Total nutrient $N_{\mathrm{T}}=10 \mu \mathrm{mol}$. Black lines are phytoplankton; grey lines are zooplankton; vertical lines indicate locations of gaps in the spectra classes we then calculated the average trophic level of zooplankton as:

$$
\langle T\rangle=\frac{\sum_{i=1}^{n} T_{Z i}}{n}
$$

These calculations only work when predators are larger than their prey. In this model predators can eat plankton larger than themselves, so for some parameters the trophic level could not be calculated.

\section{RESULTS}

\section{Size-selective feeding parameters}

Feeding parameters of planktonic invertebrates varied widely among and within major taxa (Fig. 2) and were positively related $\left(s=0.05 m+0.11, \mathrm{R}^{2}=0.27, \mathrm{p}<\right.$ 0.0001). Parameter estimates for protists were concentrated in the region of small $\mathrm{m}$ and small $s$, but estimates for other major groups such as crustaceans and gelatinous plankton were more dispersed through the parameter space. Copepods had the widest range of predator-prey size ratios, whereas krill and gelatinous taxa had the widest range of prey-size distributions. The extreme corners of the parameter space were occupied by dinoflagellates and tunicates, which also happen to be bloom-forming organisms. The variability in feeding parameters indicates that a communityaverage feeding distribution could change substantially with shifts in the community species composition.

\section{Model results}

Despite its simplicity, this model generates equilibrium plankton size spectra that meet general expectations based on empirical evidence and theoretical predictions. When nutrients are added to the system, for example, most new phytoplankton biomass is added to the largest size classes (Chisholm 1992), and the ratio of heterotrophic biomass to autotrophic biomass is positively related to phytoplankton production (Gasol et al. 1997). Spectra with larger phytoplankton support larger zooplankton, although the zooplankton spectrum also extends into larger size classes when the 

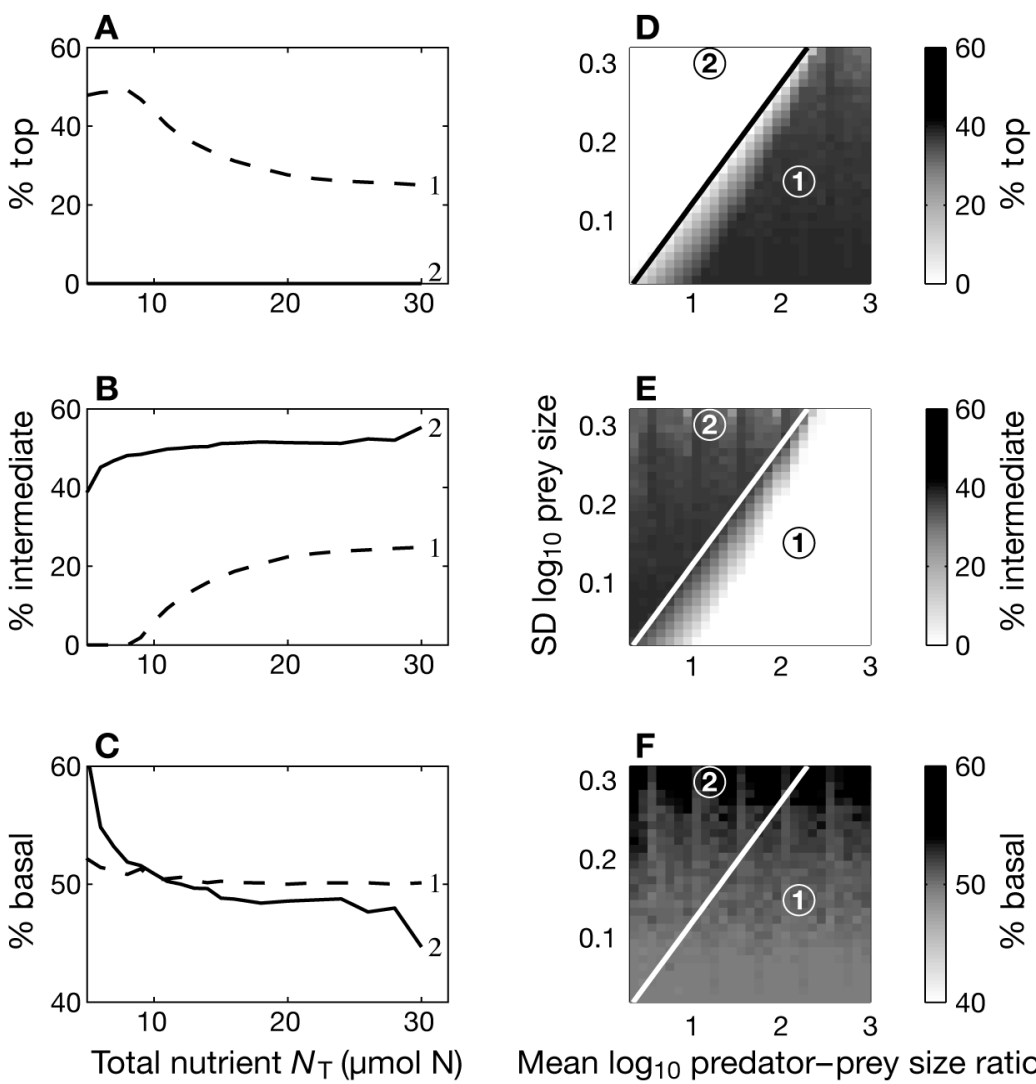

Fig. 4. Fractions of top, intermediate and basal species (A-C) vs. total nutrient $N_{\mathrm{T}}$, and (D-F) for different combinations of feeding parameters $\left(N_{\mathrm{T}}=5 \mu \mathrm{mol}\right)$. Parameters used in $(\mathrm{A}-\mathrm{C})$ correspond to those marked with circles in (D-F) $(1: m=2.2, s=0.15 ; 2: m=1.2, s=0.3)$

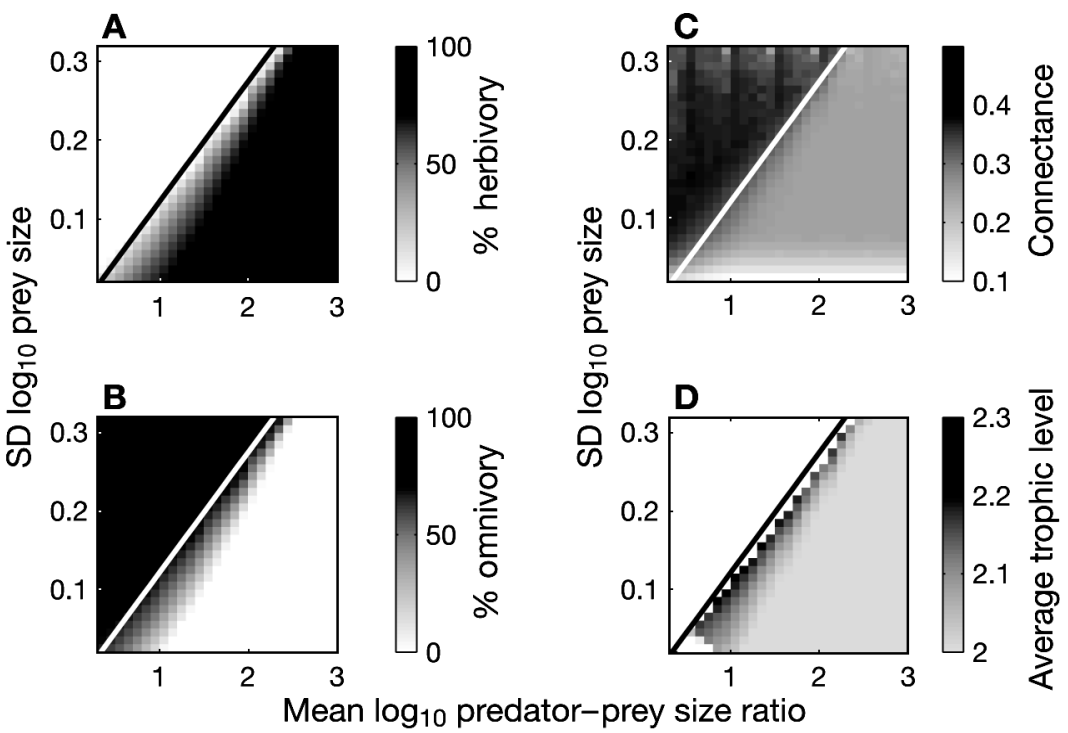

Fig. 5. (A) Percent herbivory, (B) percent omnivory, (C) connectance and (D) average trophic level of zooplankton for different combinations of feeding parameters $\left(N_{\mathrm{T}}=5 \mu \mathrm{mol}\right)$. Blank region indicates feeding parameters where average trophic level cannot be calculated predator-prey size ratio $m$ is larger (Fig. 3, e.g. C vs. D). The width of the prey size distribution affects the spectrum in less intuitive ways; for example, at higher $s$ the spectra are steeper and more nonlinear (Fig. 3, e.g. A vs. C). Below we discuss several properties of community trophic structure and size structure as they are influenced by nutrients and size-selective feeding.

\section{Trophic structure}

In this model the fractions of top, intermediate and basal size classes are strongly dependent on nutrients and the prey-size preferences of zooplankton. At the lowest nutrient levels few, if any, zooplankton can be supported and the fraction of basal species is near $100 \%$ (data not shown), but as nutrients are added and zooplankton predators are introduced, this fraction drops to around $50 \%$ (Fig. 4C,F). As more nutrients are added, there are generally fewer top predators and more intermediate ones (Fig. 4A,B), because as the zooplankton size range grows wider a smaller fraction of these zooplankton can be top predators. At low nutrients the fractions of top and intermediate predators vary widely with the feeding parameters (Fig. 4D,E), and these 2 types coexist only in a narrow diagonal window of the feeding parameter space. From here onward we will classify the feeding parameter space as Regime I where some top predators exist and Regime II where there are no top predators.

The border between the 2 regimes is somewhat sensitive to model details. The feeding probability distribution $F$ is nonzero at all size classes, so a cutoff point is needed to define predator-prey links as those with a non-trivial probability. We used a cutoff feeding probability of $10^{-5}$, which was at least 6 standard deviations from the mean for the range of feeding parameters used here. The threshold is fewer standard deviations from the mean if $s$ is large than if $s$ is small, so the fractions of top and intermediate predators are more sensitive to the cutoff value at large $s$. As a result, the slope of the border between Regimes I and II increases slightly with a higher cutoff value and decreases slightly 

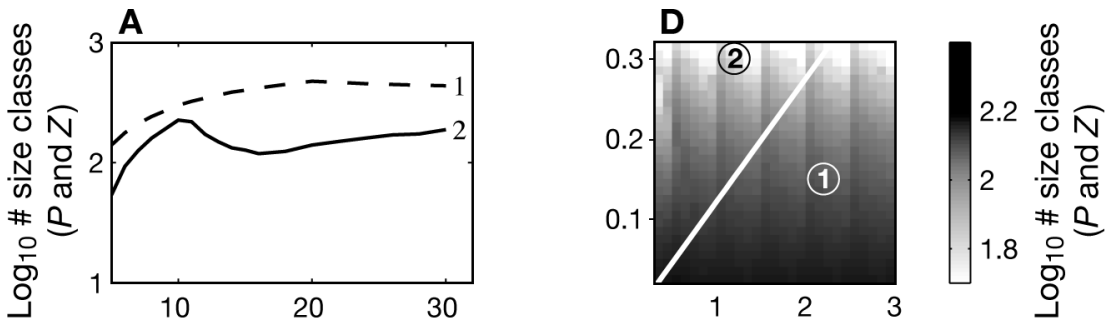

B
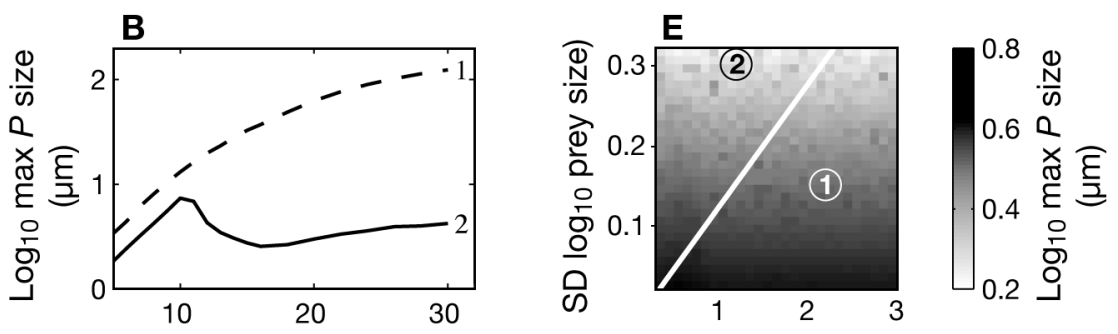

E

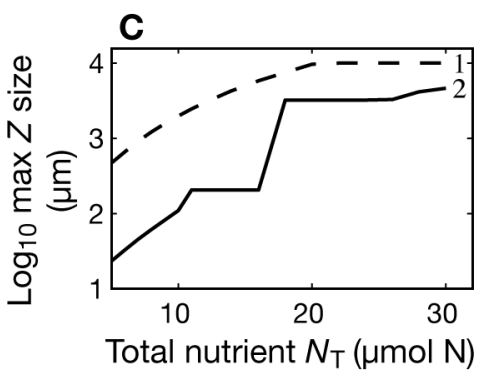

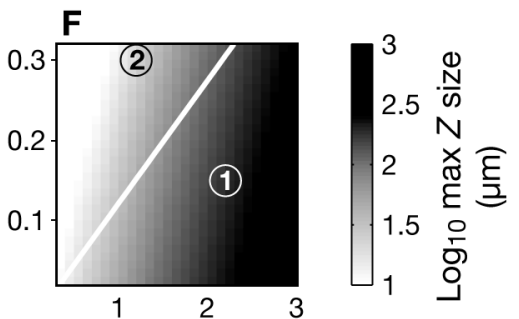

Mean $\log _{10}$ predator-prey size ratio

Fig. 6. Total size diversity ( $P$ and $Z$ ), largest phytoplankter $(P)$ size and largest zooplankter $(Z)$ size $(\mathrm{A}-\mathrm{C})$ vs. total nutrient $\left(N_{\mathrm{T}}\right)$, and $(\mathrm{D}-\mathrm{F})$ for different combinations of feeding parameters $\left(N_{\mathrm{T}}=5 \mu \mathrm{mol}\right)$. Parameters used in (A-C) correspond to those marked with circles in (D-F) $(1: m=2.2, s=0.15 ; 2: m=1.2$, $s=0.3)$

with a lower cutoff value. Qualitative aspects of the results are unaffected by the slope of the regime border.

Other trophic properties follow a similar regime pattern, and the fraction of size classes that are herbivorous is roughly proportional to the fraction of top predators. At low nutrients the fractions of herbivores and omnivores are strongly dependent on the feeding parameters, with $100 \%$ omnivores in the Regime II space (Fig. 5A,B). With more nutrients, there is a higher fraction of omnivores (data not shown), because when the phytoplankton spectrum extends to larger size classes there is more overlap of phytoplankton and zooplankton spectra. Omnivores and herbivores coexist in a diagonal window of the $m$ and $s$ parameter space. This coexistence window grows wider as nutrients are added, but the upper edge, coinciding with the border between Regime I and Regime II, remains relatively constant. Regardless of nutrient availability, herbivores and omnivores are most likely to coexist if predators are relatively specialist and not much larger than their prey.

As with the other trophic properties, the feeding parameter space defines 2 regions of connectance (Fig. 5C) and trophic level (Fig. 5D). The connectance in Regime II is generally about twice that in Regime I. This makes sense because in Regime II most zooplankton are omnivores and trophically linked to both phytoplankton and zooplankton, whereas in Regime I most zooplankton are herbivores and trophically linked only to phytoplankton. The average trophic level of zooplankton is $\langle T\rangle=2$ by definition in the region where all zooplankton are herbivores and increases to about $\langle T\rangle=$ 2.3 in the region where herbivores and omnivores coexist (Fig. 5D). Trophic level could not be calculated in Regime II, where at least some zooplankton ate some prey larger than themselves.

\section{Size structure}

Both total nutrients and zooplankton feeding preferences strongly influence the size distribution of plankton that can be supported at equilibrium (Fig. 6A-C). The total size diversity increases with the total amount of nutrients, because greater nutrient availability allows larger size classes of phytoplankton to persist, and larger phytoplankton can support larger zooplankton (Fig. 6A-C). Of the 2 feeding parameters, the prey size range $s$ chiefly controls size diversity and the maximum phytoplankter size (Fig. 6D,E). When zooplankton consume a wider range of prey sizes (larger $s$ ), the feeding rate on the preferred prey size is lower; when this peak feeding rate is lower, phytoplankton experience less predation pressure and more competition for nutrients. The smallest phytoplankton cells are more competitive, so fewer large phytoplankton size classes can persist. The numbers of phytoplankton and zooplankton size classes are closely linked, and the total diversity is lower when predators eat a wider range of prey sizes. The other feeding parameter, the mean predator-prey size ratio $m$, chiefly determines the minimum and maximum zooplankter size (Fig. 6F). The mean predator-prey size ratio controls the size offset between the phytoplankton and zooplankton spectra, such that the smallest zooplankter is about $m$ larger than the smallest phytoplankter. This offset has little effect on the actual width 

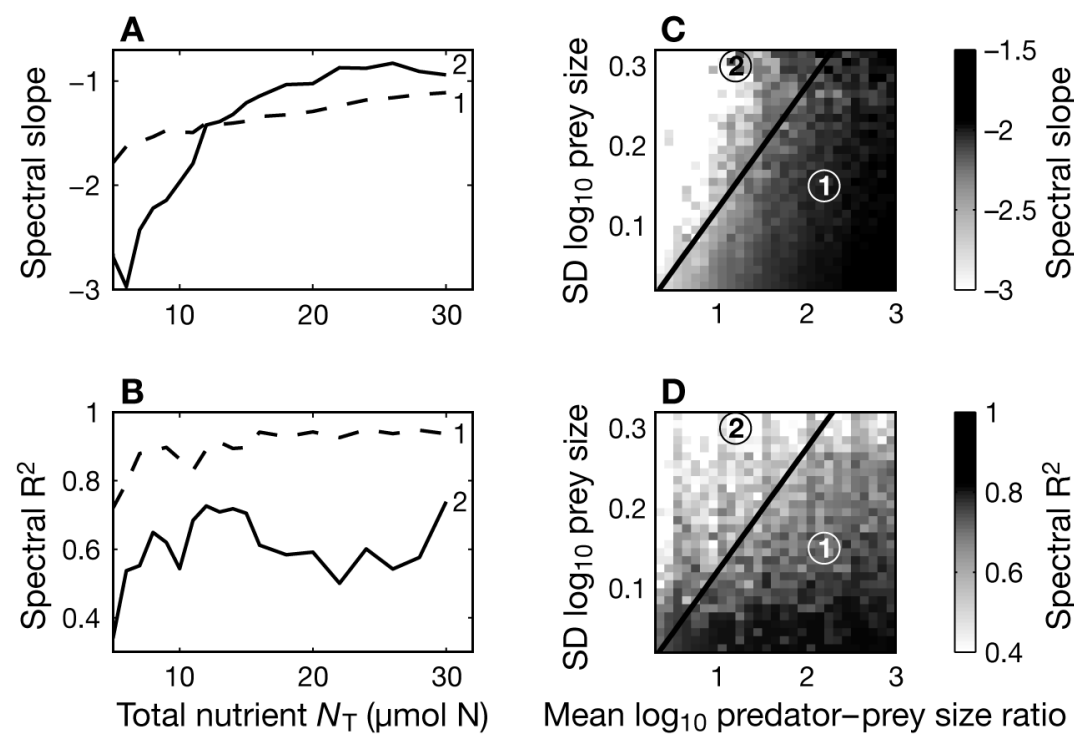

Fig. 7. Spectral slope and $\mathrm{R}^{2}(\mathrm{~A}, \mathrm{~B})$ vs. total nutrient $N_{\mathrm{T}}$ for 2 sets of parameters (1: $m=2.2, s=0.15 ; 2: m=1.2, s=0.3)$, and $(\mathrm{C}, \mathrm{D})$ for different combinations of feeding parameters $\left(N_{\mathrm{T}}=5 \mu \mathrm{mol}\right)$

of the zooplankton spectrum, so a larger $m$ leads to larger zooplankton.

The slope and nonlinearity of the size spectrum are similarly affected by both the total nutrient and feeding parameters. When there are more nutrients, larger size classes can persist, so adding nutrients produces flatter, less negative spectral slopes and higher spectral $\mathrm{R}^{2}$ values (Fig. 7A,B), in agreement with observations (Sprules \& Munawar 1986, Cavendar-Bares et al. 2001). The size spectrum also tends to be flatter and have higher $\mathrm{R}^{2}$ if $m$ is large or $s$ is small (Fig. $7 \mathrm{C}, \mathrm{D}$ ). The reasons for this are most apparent when comparing plankton size distributions that were generated with different feeding distribution parameters (Fig. 3). As described above, s mainly affects the balance of competition and predation. When $s$ is wider and the peak feeding rate is lower, phytoplankton attain more biomass in the smallest size classes but have a narrower size range. These effects are mirrored in the zooplankton spectrum, making the combined spectrum steeper. On the other hand, $m$ mainly affects the size offset between the phytoplankton and zooplankton spectra. When $m$ is small there is more overlap between the phytoplankton and zooplankton spectra, making the combined spectrum both steeper and more nonlinear. Flatter and steeper spectra correspond roughly to Regimes I and II, respectively, although the division is less clear than it is for trophic properties.

\section{Biomass}

Of the community properties studied here, biomass provides both the most predictable and the most unex- pected results. At low nutrients, the feeding distribution parameters $m$ and $s$ had little effect on plankton biomass, contributing no more than a $5 \%$ difference in biomass over the entire parameter space (data not shown). As the total nutrient increased, the total biomass, free nutrients and zooplankton biomass grew monotonically, and $\mathrm{d}(P+$ $Z) / \mathrm{d} N_{\mathrm{T}}, \mathrm{d} N / \mathrm{d} N_{\mathrm{T}}$ and $\mathrm{d} Z / \mathrm{d} N_{\mathrm{T}}$ were always positive (Fig. 8A,B). The phytoplankton biomass was an exception and failed to increase monotonically with $N_{\mathrm{T}}$ when the predator-prey size ratio was small (Fig. 8B). For $m \leq 1.7$, there were some ranges of $N_{\mathrm{T}}$ (9 to $14 \mu \mathrm{mol} N$ ) where adding nutrients resulted in lower phytoplankton biomass and negative $\mathrm{d} P / \mathrm{d} N_{\mathrm{T}}$ (Fig. 8C-E). This result is counterintuitive, particularly because the primary production (new $P$ created at each time step) was always positively related to $N_{\mathrm{T}}$. $P$ is under stronger grazer control when zooplankton predators are not too much larger than their prey.

The occasionally negative relationship between nutrients $P$ warrants some explanation. To understand the mechanism for this behavior, consider how the size spectrum changes as nutrients are added (Fig. 9) for 2 examples of feeding parameters, one from each trophic regime. For Regime I parameters $(m=2.2$ and $s=0.15)$, both the phytoplankton and zooplankton spectra grow wider over the range of $N_{\mathrm{T}}=9$ to $13 \mu \mathrm{mol} \mathrm{N}$, but the spectra remain offset and any omnivorous zooplankton get only a small fraction of their diet from zooplankton. For Regime II parameters ( $m=1.2$ and $s=0.3$ ), the phytoplankton and zooplankton spectra grow wider from $N_{\mathrm{T}}=9$ to $10 \mu \mathrm{mol} \mathrm{N}$, but there is a smaller offset between the spectra. At $N_{\mathrm{T}}=11 \mu \mathrm{mol} \mathrm{N}$ the 2 spectra are close together. A new, larger zooplankter of size $x_{\text {max }}$ can persist and gain a large biomass by feeding on both phytoplankton and zooplankton in the size range where the 2 spectra border one another. Because this part of the spectrum is heavily grazed, the previous largest phytoplankton can no longer persist and the loss of these size classes results in a lower total phytoplankton biomass. As more nutrients are added, the largest zooplankter biomass continues to grow and $P$ continues to shrink. Eventually (at $N_{\mathrm{T}}=18 \mu \mathrm{mol} \mathrm{N}$, data not shown) the largest zooplankton contain enough biomass to support a new, larger zooplankton size class at $\sim X_{\max }+m$. The new largest predator eats zooplankton of size $x_{\text {max }}$, alleviating the predation pressure on the largest phytoplankton and allowing the phytoplankton biomass to grow when nutrients are added. 

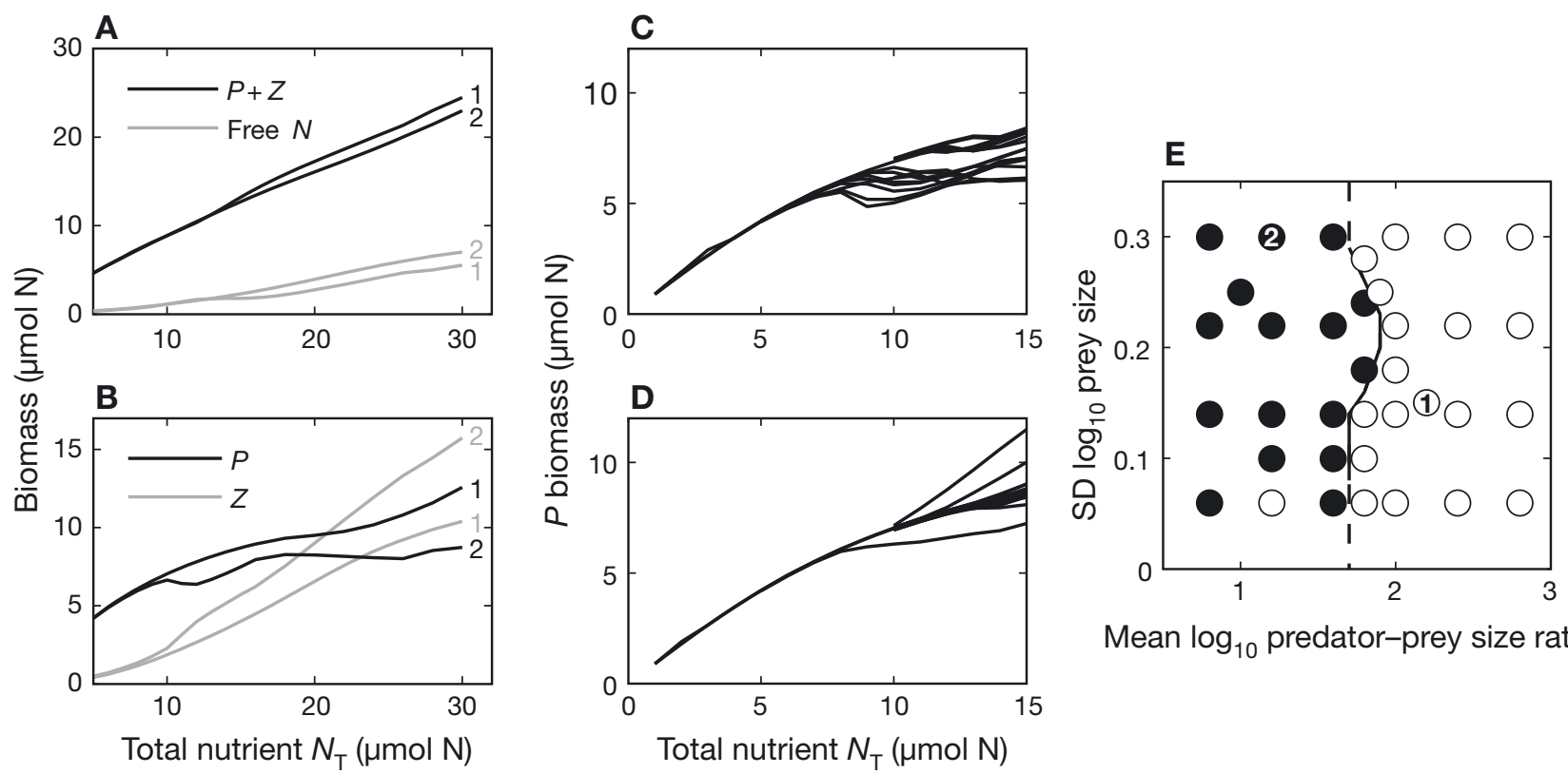

Mean $\log _{10}$ predator-prey size ratio

Fig. 8. $(\mathrm{A}, \mathrm{B})$ Total biomass $(P+Z)$, free nitrogen $(N)$, phytoplankton biomass $(P)$ and zooplankton biomass $(Z)$ vs. total nutrient $\left(N_{\mathrm{T}}\right)$ for 2 sets of parameters $(1: m=2.2, s=0.15 ; 2: m=1.2, s=0.3)$. Examples of $P$ biomass vs. $N_{\mathrm{T}}$ for feeding parameters where (C) $\mathrm{d} P / \mathrm{d} N_{\mathrm{T}}<0$ for some ranges of $N_{\mathrm{T}}$, and (D) $\mathrm{d} P / \mathrm{d} N_{\mathrm{T}}>0$ for all $N_{\mathrm{T}}$ tested. (E) Parameters used in panels C (solid circles) and $\mathrm{D}$ (open circles). Numbered parameter combinations are those used in $(\mathrm{A}, \mathrm{B})$
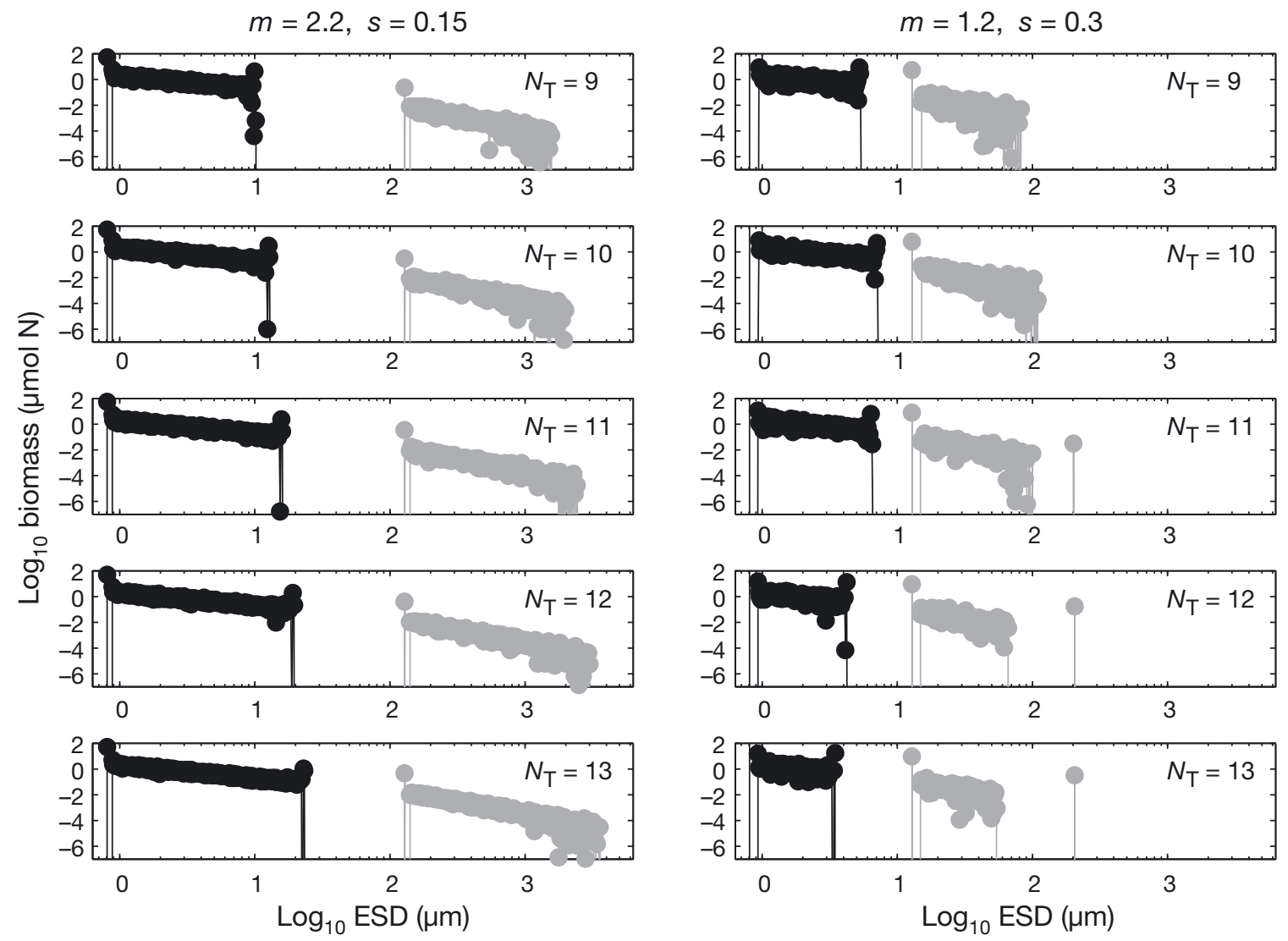

Fig. 9. Evolution of phytoplankton (black) and zooplankton (grey) biomass over $N_{\mathrm{T}}=9$ to $13 \mu$ mol for 2 feeding parameter combinations: (A) $m=2.2, s=0.15$, and (B) $m=1.2, s=0.3$. Vertical lines indicate borders of gaps in the spectra 


\section{DISCUSSION}

\section{Feeding parameters define two regimes}

Using a simple model, we found that both the total amount of nutrient and the community-average feeding preferences have a large impact on plankton community structure. Our numerical results suggest that plankton communities can be classified in 2 different regimes based on the average zooplankton characteristics. Communities in Regime I, where predators are specialized or much larger than their prey, have low omnivory, many top predators, low connectance and relatively flat size spectra. These are simple food webs with efficient transfer of biomass to larger predators. Conversely, communities in Regime II, where predators are generalists or small relative to prey, have high omnivory, no top predators, high connectance and relatively steep size spectra. These food webs are more complex, with some diffusion of biomass from larger predators to smaller ones. If the zooplankton community changes and the average predator characteristics shift from one regime to another, we would expect a major shift in fundamental community properties.

Changes in the zooplankton community composition should have different impacts on plankton trophic structure and size structure because these properties have different sensitivities to feeding parameters. A small change in the community feeding preferences can produce either no change or a major shift in food web properties, depending on the beginning and ending predator characteristics. If the feeding parameters begin and end in Regime II, for example, then the food web will have no top predators, $100 \%$ omnivory and high connectance both before and after the change. If the parameters begin in Regime II and end in Regime I, however, the food web structure can potentially be inverted from 0 to $100 \%$ top predators, 100 to $0 \%$ omnivory and high to low connectance, while the size spectrum would flatten out. Unlike the trophic properties, size structure should always be sensitive to community composition, because any small change in zooplankton feeding preferences would alter the size spectrum. As a result, a community in transition from one set of feeding parameters to another may exhibit continuous change in size structure while undergoing an abrupt shift in trophic structure.

The estimated feeding parameters (Fig. 2) can be useful for inferring how individual taxa may affect the regime classification of a predator community. Regime I taxa included most rotifers and copepods. In the model these stereotypical plankton are associated with a feeding parameter space where herbivory dominates, connectance is low, size spectra are rela- tively flat and linear, and phytoplankton biomass is consistently dependent on bottom-up control. Some taxa, including cladocerans, krill and pelagic tunicates, have feeding parameters that straddle both regimes. The regime classification is least certain for these taxa, because the slope of the regime border is influenced by model details. Nevertheless, changes in the community composition within these groups (e.g. Brinton \& Townsend 2003, Lavaniegos \& Ohman 2003) could potentially shift the predator community from one regime to the other. Regime II taxa included protists and bloom-forming organisms such as dinoflagellates, jellyfish and ctenophores. Blooms of these organisms may shift the community to one that is omnivorous and highly connected, has steep, nonlinear size spectra and is variable in its response to changes in nutrient availability.

Although blooms of some taxa may mediate shifts between regimes, the 2 regimes are probably unequally robust or stable. Here we can only speculate on disturbance and invasion scenarios because the present study explored steady-state solutions, but other work on food webs suggests a complex picture. Food webs with higher connectance are less impacted by disturbance and extinction (Law \& Blackford 1992, Dunne et al. 2002) and more difficult to invade (Romanuk et al. 2009) than those with lower connectance. On the other hand, generalist predators tend to be more successful invaders and make up more stable food webs than specialist predators (Gross et al. 2009, Romanuk et al. 2009). Our results show 2 regimes of high and low connectance, but within each regime there is a gradient of specialist to generalist feeding strategies. Communities with more generalist predators reached quasi-equilibrium fastest, regardless of connectance, and should return to a steady state more quickly after a perturbation in nutrients or biomass. The community composition, however, may be less susceptible to change if the community is already in Regime II where connectance is high. One interpretation is that zooplankton communities are most robust if predators are generalist and small relative to their prey. Taxa with these characteristics, including ctenophores and jellyfish, should be relatively successful invaders. Whereas stability may depend only on the average feeding selectivity, the tendency to shift regimes appears more imbalanced, with a greater likelihood of shifting to a more complex food web than to a simpler one.

Perhaps our most surprising discovery is that higher nutrients can sometimes result in lower phytoplankton biomass (e.g. Fig. 8). The mechanism is an extreme example of the negative feedback loop described by Brose (2008). If the predator-prey size ratio is small $(m \leq 1.7)$ and the $P$ and $Z$ spectra 
approach one another, then predators feeding at this border gain a food subsidy that enables larger zooplankton to persist and exert stronger grazer control on phytoplankton biomass. Under these conditions, the relationship between primary production and zooplankton biomass or total nutrient is strictly positive, but phytoplankton biomass can be under bottom-up or top-down control, depending on the nutrient state of the ecosystem. One implication is that although phytoplankton biomass can be estimated more easily than other properties, e.g. by ocean color, it may actually be a poor indicator of ecosystem response to environmental forcing.

\section{Model simplifications}

This relatively simple model (Eq. 1) accounts for allometric growth and size-dependent grazing but excludes other size-structured processes, and we recognize the model's limitations. Other life history parameters vary with size, including the half-saturation constant for nutrient uptake (Eppley et al. 1969), the zooplankton mortality rate (Hirst \& Kiørboe 2002) and the zooplankton feeding rate (Jürgens et al. 1996, Hansen et al. 1997). Any changes in parameter values are likely to change the shape of the size spectrum (Poulin \& Franks 2010) and the quantitative results. Based on our preliminary exploration of different parameter values, however, we expect that the general patterns observed (Figs. 4-8) are qualitatively robust. In future work we will explore the influence of other allometric scalings on plankton community properties.

Some processes, such as ontogenetic growth and reproductive output, can be modeled with size-structure (e.g. Baird \& Suthers 2007) but also vary among taxa in complex ways. These processes are irrelevant for protistan grazers but important for metazoans. Most crustacean plankton grow to larger sizes in discrete intervals through a series of molts, whereas other taxa grow continuously. There is also great taxonomic diversity in reproductive output and size of offspring relative to their parents. Although the diversity of plankton characteristics is biologically fascinating, it is also mathematically inconvenient when the goal is to keep models simple. Ontogenetic growth is often modeled by a McKendrick-von Foerster equation, but these models may be better suited to single species (e.g. Ohman \& Wood 1996) than an entire community (e.g. Law et al. 2009). In some models growth and grazing are combined in a simple flux of biomass to larger size classes (e.g. Silvert \& Platt 1978). These formulations are mathematically elegant but difficult to reconcile with the diversity of life histories in the plankton. It remains unclear how this variety can be modeled and parameterized to account for climate-driven changes in community composition.

One approach would be to model size spectra with multiple functional groups (e.g. Hood et al. 2006), using data syntheses (e.g. our Fig. 2; Brose et al. 2006a) to guide parameter selections. Even a simple model like ours could benefit from the addition of functional groups. While size is a dominant factor structuring predation, phytoplankton motility and other characteristics also influence prey selection (Atkinson 1995, Naustvoll 2000). Preferences for different prey types potentially alter food web properties, including connectance and the degree of omnivory. If phytoplankton were divided into functional groups (e.g. Hood et al. 2006), then the model could include grazer preferences for particular taxa. Ideally, zooplankton would also be separated into functional groups, because the present data synthesis (Fig. 2) shows that feeding parameters vary considerably among major taxa. Some groups could disproportionately affect the community-average parameters, and these taxa ultimately should be modeled as separate functional groups to better understand how individual taxa affect community dynamics and productivity.

\section{Relevance to climate change}

The simple size-spectrum model predicts several distinct effects of grazer characteristics on plankton community properties, but testing these theoretical predictions requires a complex data set. Ideally, we could use concurrent time series of nutrients, phytoplankton and zooplankton biomass, size structure and food web data. Unfortunately, most data sets are incomplete. Phytoplankton biomass can be estimated by remote sensing, whereas zooplankton data are more laborintensive to collect and time-consuming to analyze. Food web and size-structure properties are interrelated but rarely measured simultaneously. And although some long-term studies link temperature or climate indices to the abundance of specific predators, these studies generally lack community-level information. Even in the absence of an exemplary data set, the present study helps illuminate potential mechanisms of climate impacts on plankton communities.

Although both nutrient supply and zooplankton feeding preferences have striking effects on community properties, these processes are influenced by ocean temperature with unequal predictability. Nitrate concentration has a strong negative correlation with temperature (e.g. Kamykowski \& Zentara 1986), and the total nitrogen will be more limited in warmer, more stratified waters. By reducing nutrient availability, warmer temperatures most likely will lead to a decline 
in total plankton biomass and zooplankton biomass. Phytoplankton biomass, however, may actually increase in warmer, more nutrient-limited waters if most zooplankton are not too much larger than their prey.

The influence of temperature on specific predators is more inconsistent, complicating any speculation on how climate affects planktonic ecosystems. Many generalist predators have abundances that correlate with temperature, the PDO or the North Atlantic Oscillation (NAO), but the direction of correlation varies by species, study period and region (Table S2 in the supplement at www.int-res.com/articles/suppl/m413p001_ supp.pdf). In a given region, environmental forcing potentially affects predator populations in 2 ways: ocean currents transport predators to local waters from warmer or cooler latitudes where they are more prevalent (Attrill et al. 2007, Lavaniegos \& Ohman 2007), or temperature affects the growth rates of predators within local waters (Purcell \& Decker 2005). Either process will alter the local community composition and may change the average feeding preferences. In order to predict the relative abundances of zooplankton taxa in a specific place, we need to know both how climate affects regional circulation and how temperature affects the life histories of important species.

The relationship between temperature and zooplankton abundance may be key for understanding some observations that seem to contradict the theory of bottom-up control. In the North Sea, for example, chlorophyll a biomass increased from 1980 to 2002 despite a decline in available nitrogen and phosphorus (McQuatters-Gollop et al. 2007). From the mid-1980s onward there was a rise in jellyfish frequency, apparently in response to a rising NAO index and inflow from the North Atlantic (Attrill et al. 2007). Jellyfish are identified in our analysis as having a small predatorprey size ratio, and blooms of these predators could have shifted the community to one where the relationship between nutrients and phytoplankton biomass becomes variable.

\section{SUMMARY}

Here we demonstrate that a top-down mechanism, size-selective feeding, can influence community properties with an effect size comparable to that of nutrient inputs. Every aspect of community food web and size structure could be altered as much by a shift in predator dominance from one regime to another as by an order-of-magnitude change in the total nutrients (Figs. 4-7). Total biomass depends mainly on nutrient availability; our model predicts that biomass would adjust in proportion to any change in the total nutrients but could change by no more than $\sim 5 \%$ as a result of extreme shifts in predator characteristics (Fig. 8). Yet the predator-prey size ratio does have a critical impact on the biomass of phytoplankton, because this feeding parameter determines whether the relationship between nutrients and phytoplankton biomass is always positive or sometimes negative. Changes in the predator community are likely to resonate throughout the entire ecosystem, because plankton size distributions affect how much food is available to fish larvae (Hahm \& Langton 1984, Pearre 1986) and how quickly organic carbon is exported from surface waters in the form of fecal pellets (Turner 2002). Size-selective feeding fundamentally affects plankton community structure and is a likely mechanism of change in marine and aquatic ecosystems where community composition varies with temperature.

Acknowledgements. We thank M. Ohman, A. Lucas and anonymous reviewers for helpful comments on early drafts of the manuscript. This work was funded by the National Science Foundation as part of the California Current Ecosystem LTER (OCE-0417616).

\section{LITERATURE CITED}

Armstrong RA (2003) A hybrid spectral representation of phytoplankton growth and zooplankton response: the 'control rod' model of plankton interaction. Deep-Sea Res II 50:2895-2916

Atkinson A (1995) Omnivory and feeding selectivity in five copepod species during spring in the Bellinghausen Sea, Antarctica. ICES J Mar Sci 52:385-396

Attrill MJ, Wright J, Edwards M (2007) Climate-related increases in jellyfish frequency suggest a more gelatinous future for the North Sea. Limnol Oceanogr 52:480-485

Baird M, Suthers IM (2007) A size-resolved pelagic ecosystem model. Ecol Model 203:185-203

Behrenfeld MJ, O'Malley RT, Siegel DA, McClain CR and others (2006) Climate-driven trends in contemporary ocean productivity. Nature 444:752-755

Brinton E, Townsend A (2003) Decadal variability in abundances of the dominant euphausiid species in southern sectors of the California Current. Deep-Sea Res II 50: $2449-2472$

Brose U (2008) Complex food webs prevent competitive exclusion among producer species. Proc R Soc Lond B 275: 2507-2514

> Brose U, Jonsson T, Berlow EL, Warren P, Banasek-Richter C, Bersier LF, Blanchard JL (2006a) Consumer-resource body-size relationships in natural food webs. Ecology 87 : 2411-2417

Brose U, Williams RJ, Martinez ND (2006b) Allometric scaling enhances stability in complex food webs. Ecol Lett 9: 1228-1236

Brown JH, Gillooly JF, Allen AP, Savage VM, West GB (2004) Toward a metabolic theory of ecology. Ecology 85: 1771-1789

Cavendar-Bares KK, Rinaldo A, Chisholm SW (2001) Microbial size spectra from natural and nutrient enriched ecosystems. Limnol Oceanogr 46:778-789

Chisholm SW (1992) Phytoplankton size. In: Falkowski PG, 
Woodhead AD (eds) Primary productivity and biogeochemical cycles in the sea. Plenum Press. New York, p 213-237

Cohen JE, Newman CM (1985) A stochastic theory of community food webs: I. Models and aggregated data. Proc R Soc Lond B 224:421-448

> Cohen JE, Pimm SL, Yodzis P, Saldaña J (1993) Body sizes of animal predators and animal prey in food webs. J Anim Ecol 62:67-78

- Dunne J, Williams R, Martinez N (2002) Network structure and biodiversity loss in food webs: robustness increases with connectance. Ecol Lett 5:558-567

Edwards CA, Powell TM, Batchelder HP (2000) The stability of an NPZ model subject to realistic levels of vertical mixing. J Mar Res 58:37-60

Eppley RW, Rogers JN, McCarthy JJ (1969) Half-saturation constants for uptake of nitrate and ammonium by marine phytoplankton. Limnol Oceanogr 14:912-920

Field DB, Baumgartner TR, Charles CD, Ferreira-Bartrina V, Ohman MD (2006) Planktonic foraminifera of the California Current reflect 20th century warming. Science 311: 63-66

> Franks PJS, Wroblewski JS, Flierl GR (1986) Behavior of a simple plankton model with food-level acclimation by herbivores. Mar Biol 91:121-129

Gasol J, del Giorgio P, Duarte C (1997) Biomass distribution in marine planktonic communities. Limnol Oceanogr 42: 1353-1363

> Gross T, Rudolf L, Levin SA, Dieckmann U (2009) Generalized models reveal stabilizing factors in food webs. Science 325:747-750

> Hahm W, Langton R (1984) Prey selection based on predator/prey weight ratios for some northwest Atlantic fish. Mar Ecol Prog Ser 19:1-5

Hansen B, Bjørnsen PK, Hansen PJ (1994) The size ratio between planktonic predators and their prey. Limnol Oceanogr 39:395-403

Hansen PJ, Bjørnsen PK, Hansen BW (1997) Zooplankton grazing and growth: scaling within the $2-2,000-\mu \mathrm{m}$ body size range. Limnol Oceanogr 42:687-704

> Hereu CM, Lavaniegos BE, Gaxiola-Castro G, Ohman MD (2006) Composition and potential grazing impact of salp assemblages off Baja California during the 1997-1999 El Niño and La Niña. Mar Ecol Prog Ser 318:123-140

> Hirst AG, Kiørboe T (2002) Mortality of marine planktonic copepods: global rates and patterns. Mar Ecol Prog Ser 230:195-209

$>$ Hood RR, Laws EA, Armstrong RA, Bates NR and others (2006) Pelagic functional group modeling: progress, challenges and prospects. Deep-Sea Res II 53:459-512

Hooff RC, Peterson WT (2006) Copepod biodiversity as an indicator of changes in ocean and climate conditions of the northern California current ecosystem. Limnol Oceanogr 51:2607-2620

> Jennings S, Warr KJ, Mackinson S (2002) Use of size-based production and stable isotope analyses to predict trophic transfer efficiencies and predator-prey body mass ratios in food webs. Mar Ecol Prog Ser 240:11-20

> Jürgens K, Wickham SA, Rothhaupt KO, Santer B (1996) Feeding rates of macro- and microzooplankton on heterotrophic nanoflagellates. Limnol Oceanogr 41:1833-1839

Kamykowski D, Zentara SJ (1986) Predicting plant nutrient concentrations from temperature and sigma- $t$ in the upper kilometer of the world ocean. Deep-Sea Res A 33:89-105

Kot M, Lewis MA, van den Driessche P (1996) Dispersal data and the spread of invading organisms. Ecology 77 : 2027-2042
Lavaniegos BE, Ohman MD (2003) Long-term changes in pelagic tunicates of the California Current. Deep-Sea Res II 50:2473-2498

Lavaniegos BE, Ohman MD (2007) Coherence of long-term variations of zooplankton in two sectors of the California Current System. Prog Oceanogr 75:42-69

> Law R, Blackford JC (1992) Self-assembling food webs: a global viewpoint of coexistence of species in LotkaVolterra communities. Ecology 73:567-578

Law R, Plank M, James A, Blanchard J (2009) Size-spectra dynamics from stochastic predation and growth of individuals. Ecology 90:802-811

McCann K, Hastings A, Huxel GR (1998) Weak trophic interactions and the balance of nature. Nature 395:794-798

McQuatters-Gollop A, Raitsos DE, Edwards M, Pradhan Y, Mee LD, Lavendar SJ, Attrill MJ (2007) A long-term chlorophyll data set reveals regime shift in North Sea phytoplankton biomass unconnected to nutrient trends. Limnol Oceanogr 52:635-648

Moloney CL, Field JG (1989) General allometric equations for rates of nutrient uptake, ingestion, and respiration in planktonic organisms. Limnol Oceanogr 34:1290-1299

Moloney CL, Field JG (1991) The size-based dynamics of plankton food webs. I. A simulation model of carbon and nitrogen flows. J Plankton Res 13:1003-1038

Naustvoll LJ (2000) Prey size spectra and food preferences in thecate heterotrophic dinoflagellates. Phycologia 39: 187-198

> Neubert MG, Kot M, Lewis MA (1995) Dispersal and pattern formation in a discrete-time predator-prey model. Theor Popul Biol 48:7-43

> Neubert MG, Blumenshine SC, Duplisea DE, Jonsson T, Rashleigh B (2000) Body size and food web structure: testing the equiprobability assumption of the cascade model. Oecologia 123:241-251

Neutel AM, Heesterbeek JAP, van de Koppel J, Hoenderboom $\mathrm{G}$ and others (2007) Reconciling complexity with stability in naturally assembling food webs. Nature 449:599-602

> Ohman M, Wood S (1996) Mortality estimation for planktonic copepods: Pseudocalanus newmani in a temperate fjord. Limnol Oceanogr 41:126-135

Pearre S Jr (1980) Feeding by Chaetognatha: the relation of prey size to predator size in several species. Mar Ecol Prog Ser 3:125-134

> Pearre S Jr (1986) Ratio-based trophic niche breadths of fish, the Sheldon spectrum, and the size-efficiency hypothesis. Mar Ecol Prog Ser 27:299-314

> Petchey OL, Beckerman AP, Riede JO, Warren PH (2008) Size, foraging, and food web structure. Proc Natl Acad Sci USA 105:4191-4196

Poulin F, Franks P $(2010)$ Size-structured planktonic ecosystems: constraints, controls and assembly instructions. J Plankton Res (in press)

Purcell JE, Decker MB (2005) Effects of climate on relative predation by scyphomedusae and ctenophores on copepods in Chesapeake Bay during 1987-2000. Limnol Oceanogr 50:376-387

Richardson AJ, Schoeman DS (2004) Climate impact on plankton ecosystems in the northeast Atlantic. Science 305:1609-1612

> Roemmich D, McGowan J (1995) Climate warming and the decline of zooplankton in the California Current. Science 267:1324-1326

> Romanuk TN, Zhou Y, Brose U, Berlow EL, Williams RJ, Martinez ND (2009) Predicting invasion success in complex ecological networks. Philos Trans R Soc Lond B 364:1743-1754 
Sheldon RW, Prakash A, Sutcliffe WH Jr (1972) The size distribution of particles in the ocean. Limnol Oceanogr 17: $327-340$

Sheldon RW, Sutcliffe WH Jr, Paranjape MA (1977) Structure of pelagic food chain and relationship between plankton and fish production. J Fish Res Board Can 34: 2344-2353

Silvert W, Platt T (1978) Energy flux in the pelagic ecosystem: a time-dependent equation. Limnol Oceanogr 23:813-816

Smith PE, Moser HG (2003) Long-term trends and variability in the larvae of Pacific sardine and associated fish species of the California Current region. Deep-Sea Res II 50: 2519-2536

Sprules WG, Munawar W (1986) Plankton size spectra in rela-

Editorial responsibility: Alain Vézina,

Dartmouth, Canada tion to ecosystem productivity, size, and perturbation. Can J Fish Aquat Sci 43:1789-1794

Steele JH, Frost BW (1977) The structure of plankton communities. Philos Trans R Soc Lond B 280:485-534

Steele JH, Henderson EW (1981) A simple plankton model. Am Nat 117:676-691

Stock C, Powell T, Levin S (2008) Bottom-up and top-down forcing in a simple size-structured plankton dynamics model. J Mar Syst 74:134-152

Tang EPY (1995) The allometry of algal growth rates. J Plankton Res 17:1325-1335

Turner JT (2002) Zooplankton fecal pellets, marine snow and sinking phytoplankton blooms. Aquat Microb Ecol 27: 57-102

Submitted: March 8, 2010; Accepted: June 28, 2010

Proofs received from author(s): August 4, 2010 